\title{
REVISÃO DE UM ITINERÁRIO FILOSÓFICO: DA IDEIA DE CULTURA AO CONCEITO DE FORMA SIMBÓLICA ${ }^{1}$
}

Joaquim Braga ${ }^{2}$

\begin{abstract}
The subject of this paper focuses on the notion of "culture" encapsulated in Aufklärung and on the concept of "symbolic form" proposed in the work of Ernst Cassirer. Although the two appear to suggest a mere historical continuity, supported in part by the relationship between the thought of Immanuel Kant and Cassirer's philosophy of culture, there is, from a certain philosophical point of view, a distinctive itinerary that allows us to glimpse the many changes that have resulted from the theoretical articulation of both. Making this itinerary intelligible and identifying conceptual differences that better define it, will be the main purposes of our reflection.
\end{abstract}

Keywords: culture; symbolic forms; meaning; sensitivity

Resumo: O conteúdo deste texto tem como eixos estruturantes a noção de "cultura" legada pela Aufklärung e a concepção de "forma simbólica" presente na obra de Ernst Cassirer. Embora as duas aparentem sugerir uma mera continuidade histórica, suportada, em parte, pela relação entre o pensamento de Immanuel Kant e a filosofia da cultura de Cassirer, há, do ponto de vista filosófico, um itinerário singular que nos permite vislumbrar as múltiplas transformações teóricas que resultam da articulação de ambas. Tornar esse itinerário visível e identificar as diferenças conceptuais que melhor o definem, serão os principais objectivos da nossa reflexão.

Palavras-chave: cultura; formas simbólicas; sentido; sensibilidade

\section{Introdução}

Apartar das várias capacidades reflexivas do sujeito uma única que faça jus à percepção do universo social a que este pertence, não é uma operação teórica linear, nem tão-pouco, se atendermos às suas ramificações históricas, pode ser considerada como uma operação que tem sempre por base o mesmo projecto humano. De facto, a faculdade de compreender culturalmente as actividades que se desenrolam no universo social - e sem ter de sair dele - é uma possibilidade de distanciamento crítico, que, longe de seguir um mero telos terapêutico, tem permitido estabelecer pontos de reflexão sobre a relação entre indivíduo e sociedade, bem como linhas de acção que a sustentam e transformam. Mas, e é essa a nossa questão fundamental, o que vem a ser objectivado quando falamos de "compreender culturalmente" a vida do sujeito?

Braga, J. (2012). Revisão de um itinerário filosófico: da ideia de cultura ao conceito de forma simbólica. DEDiCA. REVISTA DE EDUCAÇÃO E HUMANIDADES, 3 (2012) março, 43-60 
E, por outro lado, qual é a relevância que o conceito filosófico de "forma simbólica" tem para a organização dessa compreensão, o mesmo é dizer, para a ideia de "cultura"?

\section{Do "bárbaro" ao "cultivado": observação e hierarquização}

Os pensadores da Aufklärung definiram a ideia de "cultura" a partir de uma lógica filosófica com um cunho essencialmente teleológico-normativo. Ancorado numa visão antropológica da cultura como finalidade da natureza, Immanuel Kant, por exemplo, define o universo cultural como o espaço humano onde é acolhida a ideia de moralidade e, com esta, a inevitável forma do imperativo categórico. A base de observação kantiana do universo social repousa numa categorização hierárquica da existência cultural do sujeito. O "bárbaro", o "civilizado" e o "cultivado" são os três níveis de distinção social que resultam da articulação transcendental entre cultura e natureza. Assim, o nível superior seria ocupado pelo cultivado, pois é aquele sujeito que, educado pela arte e pela ciência, abdica da corporalidade e põe entre parêntesis todas as inclinações sensoriais. O nível intermédio é entregue ao civilizado, dada a sua incapacidade de viver plenamente em concordância com a razão ética e ao facto de agir única e exclusivamente mediante as aparências do seu estatuto social. A entrada no espaço humano civilizado não garante a total efectivação da ideia de moralidade, ou seja, embora o estádio da civilização seja onde ocorre a aplicação desta ideia, a sua materialização efectiva no universo social está sempre condicionada pelos interesses práticos dos agentes ${ }^{3}$. Do bárbaro - que ocupa o nível inferior na hierarquia - fica-nos, pois, como ocorria na distinção clássica entre humanidade e animalidade, a imagem de um sujeito que é incapaz de ascender à condição humana exigida pelo progresso da razão, mergulhado que está na bestialidade dos instintos, na esfera dos interesses imediatos, sendo, nessa exacta medida, desprovido de qualquer faculdade superior que lhe garanta a programação do tempo em função do futuro.

Com efeito, a cultura, vista segundo este processo de moralização proposto por Kant, representaria o estádio normativo da razão, cujos conteúdos fundacionais seriam dados pelo conjunto de princípios ético-normativos inerentes às formas de conhecimento e acção humanas; o conceito de civilização delimitaria, por sua vez, o estádio vinculativo da razão a esses mesmos princípios, pressupondo-se, de antemão, que a sua aplicação nunca chega a 
ser totalmente realizada. Daí que, como se pode inferir da visão do filósofo de Königsberg, a cultura tenda a servir no pensamento moderno do século dezoito uma lógica da comparação (Luhmann, $1985)^{4}$, contribuindo assim para uma classificação e hierarquização de práticas sociais e de valores éticos.

Uma concepção diferente da de Kant pode ser encontrada na obra de Johann Gottfried Herder. Apesar de Herder procurar inquirir a linha de separação entre os traços culturais e os traços biológicos do ser humano, ele afasta-se, porém, das concepções estritamente normativas da Aufklärung. Enquanto Kant encara a ideia de cultura a partir de um sensus moralis dado pelo primado legislador da razão sobre as propensões arbitrárias do agir humano, isto é, a cultura seria a etapa no desenvolvimento do ser que elevaria este a uma superioridade moral, já para Herder, pelo contrário, o homem é histórica e socialmente um ser cultural - tal pode ser a síntese da nova concepção proposta -, havendo, nesse aspecto, várias formas de expressão culturais que, não se situando numa mera esfera epifenoménica, podem ser detectáveis no domínio das actividades realizadas pelo homem. O conceito de "cultura" deixou de se referir apenas aos fenómenos de uma sociedade ilustrada, bem cultivada, perdendo as conotações valorativas do intelectualismo elitista da Hochkultur, que considerava o cultural como o predicado supremo de um sujeito com acesso a uma formação superior. E é por via desse efeito de descentralização do cultural que Edward Burnett Tylor - um dos fundadores da Cultural Anthropology - veio a empregar os conceitos de cultura e de civilização de forma indiferenciada ${ }^{5}$.

\section{Processos de simbolização e formas de expressão}

Ora a visão de que a cultura é, por princípio, um universo intrínseco a todos os seres humanos, como veio a ser defendido por Herder, potencia uma verdadeira descentralização dos fenómenos culturais. A questão, porém, coloca-se com as fundações filosóficas que alinham essa expansão. Pois se na relação hierárquica entre cultura e civilização encontramos a razão como princípio mediador, impõe-se agora perguntar qual será o novo princípio que fará jus ao ideal esboçado por Herder e prosseguido por Tylor, dando assim resposta à emergência das formas de expressão na observação da natureza cultural do ser humano.

Compreender as formas de expressão culturais é implicar os processos de simbolização na criação e apreensão da realidade. A 
cultura, entendida como modo de auscultação dessa correlação, passa a ser inteligível, como aliás refere Leslie White, quando o desenvolvimento da capacidade de simbolizar se abre à expressão (White, 19592: 3). Na concepção de Ernst Cassirer, a ideia de cultura só pode ser analisada a partir das múltiplas formas de mediação culturais. Assim, uma Philosophie der symbolischen Formen teria a tarefa teórica de trazer à reflexão a polissemia simbólica de «todas as formas de compreender o mundo" (alle Richtungen des Weltverstehens) (Cassirer, 19943:16), mais concretamente o conjunto das formas simbólicas composto pelo mito, religião, linguagem, arte, ciência, técnica, etc. Apesar dos traços distintivos que as separam, pois as estruturas que configuram a base de cada uma obedecem a operações simbólicas específicas, todas estas formas põem em jogo o modo como o sujeito sai da sua esfera individual e, encetando contacto com a esfera do "outro", é capaz de obter conhecimento da realidade que o envolve. Trata-se, portanto, de ver o conhecimento que o sujeito adquire através das formas simbólicas dentro de um movimento de alteridade; movimento esse que coloca o ser humano no espaço aberto pela mediação.

A abrangência estabelecida pela interpretação da cultura através dos processos de simbolização assinala uma clara demarcação face ao legado racionalista. Por isso, a filosofia das formas simbólicas não é, como às vezes se afirma, uma mera aplicação da crítica da razão kantiana a outras de formas de conhecimento da experiência humana. A transformação da Kritik der Vernunft numa Kritik der Kultur, como sugere Cassirer no primeiro volume da sua obra (Cassirer, 1994: 11), pressupõe igualmente uma recondução das questões gnoseológicas para o espectro cultural das formas de articulação. Mas este passo só é verdadeiramente dado e efectivado graças à inclusão do papel activo da expressão nos processos cognitivos, ou seja, segundo Cassirer, a organização do conhecimento está indissociavelmente ligado à «actividade livre da expressão» (Cassirer, 1994": 175). Com o primado da expressão não só se transpõem as reflexões filosóficas baseadas na inquirição dos processos puros da consciência, como também se remetem os domínios da construção da subjectividade para as estruturas sígnicas sensíveis que suportam as formas de mediação (Ibidem). Abandonado o misticismo das concepções que vêem na imediaticidade as portas de acesso à consciência do sujeito, passa a ser na geração e comunicação de horizontes de sentido que a construção da subjectividade adquire as suas potencialidades 
configuradoras. Numa palavra: é na criação da forma que o sujeito se individualiza.

Partindo desta última premissa, poder-se-á então dizer que cada forma simbólica representa um modo singular de articular e observar as experiências humanas, já que os seus elementos estruturantes não se deixam reduzir a uma mera função indexical, a uma relação contingente entre signo e objecto. Aquilo a que chamamos mundo - e que sobrevém dessa articulação -, não sendo apreendido como entidade ontológica imutável, passa a ter várias possibilidades de relação e de sentido, ou, como será mais tarde sustentado por Nelson Goodman, a actividade e a compreensão simbólicas reservam-nos várias "versões do mundo" (Ways of worldmaking) (Goodman, 1990). Deste modo, o despontar de novas formulações da realidade obedece à possibilidade de as experiências humanas poderem ser ordenadas segundo critérios de distinção, uma vez que os fenómenos que não se prestam a operações de diferenciação deixam de poder ser representados internamente pelo sujeito, isto é, e na mesma linha de argumentação, não entram nas versões do mundo.

\section{Forma, sentido, sensibilidade}

Indaguemos agora as implicações que a questão da expressão tem na génese do conceito de forma simbólica.

No sistema filosófico de Cassirer, as formas simbólicas são estruturas que dão consistência aos processos de simbolização, à dialéctica criativa entre conhecimento e acção, e à permanência e transformação que resultam da dinâmica da correlação destes dois últimos. "Criativa", evidenciamos nós, porque cada forma de mediação nunca se inscreve sem a intercessão da sensibilidade (Sinnlichkeit) e da imaginação (Einbildungskraft) na articulação dos seus elementos materiais. O esquematismo que acompanha cada forma simbólica representa uma verdadeira resolução da polaridade entre idealidade conceptual e contingência material, ainda bem presente na filosofia transcendental de Kant - embora o filósofo de Königsberg, ao destacar o papel da Sinnlichkeit na intelecção dos fenómenos, contribua de forma decisiva para a vinculação do símbolo à sua realidade material. Com o conceito de forma simbólica são expostos dois momentos que se cruzam:

1) O momento em que é exteriorizado um conteúdo espiritual através de uma configuração material; 
2) e o momento em que esse processo de exteriorização e materialização é interiorizado pelo sujeito (Cassirer, 1994 ${ }^{4}$ 175)

Há, aqui, um claro distanciamento de Cassirer em relação à filosofia kantiana, uma vez que Kant concebe, por exemplo, o juízo estético fora da esfera das emoções, do material, do sensível, do corporal. O gosto "cultivado", sendo uma faculdade desinteressada, capaz de intuir a forma na sua autenticidade intelectual, distingue-se do gosto "bárbaro", já que este último é ainda dominado pelo interesse das paixões e das inclinações somáticas (Kant, 1908: § 41-42, 296-302). Tanto a supressão do sensível como a exaltação da significação pura são liminarmente rejeitadas por Cassirer. Ele vai precisamente ultrapassar a dicotomia kantiana ao transformar o esquematismo numa correlação indivisível entre "sensibilidade" e "sentido" (Sinn), surgindo assim a idealidade conceptual não como uma função a priori do entendimento, mas antes como um resultado possível dessa correlação, isto é, dos dois momentos que geram a constituição da forma.

A refundação do esquematismo kantiano vai possibilitar uma nova interpretação das estruturas simbólicas. Os símbolos, graças à sua manifestação e constituição material através de signos sensíveis (sinliche Zeichen), estão indissociavelmente ligados à sensibilidade. Logo, o trabalho da expressão vai evidenciar quer a exteriorização de um elemento significativo quer a preparação de um elemento significante, estando, neste sentido, dependente das condições materiais que possibilitam a organização sensível da forma que incorpora. Que este duplo trabalho não possa ser compreendido como uma mera conversão, imediata e linear, de um conteúdo mental numa configuração física, tal decorre do facto de qualquer acto expressivo estar sempre sujeito às múltiplas resistências impostas pelas estruturas materiais. Quando falamos de uma articulação entre sentido e sensibilidade, estamos, em rigor, a apontar simultaneamente para uma tensão fundamental que se estabelece entre exteriorização e materialização. $E$ daqui também se infere que, devido a essa tensão, a esse hiatus temporalis que ocorre até à consolidação do acto expressivo, o próprio sensível da materialidade "ganha tempo" para se poder expressar na criação do sentido. A forma nunca transmove apenas um conteúdo mental; há, por assim dizer, informações discretas da sensibilidade que também nela são reintegradas.

4. 1. O corpo como arqui-fenómeno expressivo 
Existe uma certa tendência generalizada para definir a cultura como o complexo de representações e identificações de um determinado corpo social de indivíduos. Os fenómenos culturais seriam, por essa ordem, escrutados segundo uma observação teórico-semiótica dos seus conteúdos principais, bastando para isso encontrar os elementos semânticos daquilo que é intencionalmente simbolizado ${ }^{6}$. Deste modo os elementos sensíveis do símbolo deixariam de ter qualquer relevância para a construção da observação; e, como se verifica, por exemplo, em certas visões etnográficas do religioso - cujas descrições de práticas cerimoniais tendem a partir de uma mera lógica de adequação entre símbolo e simbolizado -, os processos de simbolização ficariam assim reduzidos ao seu conteúdo proposicional. As linhas de separação entre estrutura e acção são, em rigor, uma tendência dicotómica do pensamento moderno, e foram extremamente realçadas com 0 discurso sobre os processos semiósicos da linguagem, nomeadamente com aquele que emerge da distinção saussuriana entre langue e parole. Porém, a ideia de cultura estaria limitada à programação de um património de valores e representações (e o estudo das relações interculturais ficaria restringido ao grau de comparação entre esses mesmos valores e representações), se se seguisse, na observação dos fenómenos culturais, uma lógica puramente linguística, que apenas vê nos eventos comunicacionais a actualização das estruturas dos sistemas de linguagem.

Mas, como bem sabemos, falar não é somente dizer algo a alguém - é, também, ser ouvido. Aquilo que é pronunciado e aquilo que é percepcionado constituem dois momentos estruturantes da linguagem, cuja articulação se manifesta quer nas operações mentais quer nas operações motoras dos interlocutores. A comunicação está tão dependente dos processos de percepção quanto a contemplação de uma obra de arte, já que a mediação simbólica remete para as dimensões sensíveis da criação da forma, para o contexto expressivo que a liga à percepção, e não apenas, como pretendia Leslie White com a sua definição de cultura baseada na distinção saussuriana entre estruturas sincrónicas e estruturas diacrónicas, para um "contexto extra-somático" (White, 1959: 233234). E é precisamente esse requisito do sensível que leva Cassirer a encontrar na correlação corpo-alma a forma "exemplar" - o arquifenómeno - de todas as outras formas simbólicas (Cassirer, 19943: 117). Por um lado, o envolvimento do corpo na questão da forma afasta as tradicionais polarizações idealistas e materialistas, ainda 
tão presentes nas equívocas concepções de "cultura espiritual" e "cultura material". Implicar a experiência do corpo na estruturação das articulações simbólicas é, por outro lado, transpor quer a ideia cartesiana de uma visão mecanicista do corpo quer as teses meramente funcionalistas defendidas pela filosofia da técnica, que, embora pretenda envolver o corpo na dinâmica cultural, acaba por conceber os artefactos tecnológicos como puras extensões ou projecções do corpo humano (Kapp, 1877).

Com efeito, o sentido de um fenómeno cultural nunca pode ser encontrado apenas através do seu significado discursivo ou da sua equivalência textual. A inclusão da corporalidade nos processos de simbolização exemplifica, nesse aspecto, tanto a unidade expressiva que é gerada pelo fenómeno cultural, como a irredutibilidade deste a qualquer interpretação positivista. Por isso, a diferença fundamental que distingue a Filosofia das formas simbólicas de uma aproximação semiótica aos fenómenos culturais está já contida, precisamente, na noção de intermutabilidade decorrente da articulação entre sensibilidade e significação. É esta diferença que, ao assinalar o simbólico como a esfera das operações humanas através da qual se processa o encontro entre o substrato sensível e o substrato inteligível da forma, nos impede de compreender os objectos culturais como meras codificações - ou actualizações - de estruturas semiológicas pré-estabelecidas. Resultando o simbólico de operações incorporadas, quer dizer, inscritas no e pelo corpo, a cultura nunca poderá ser observada e substituída por um simples sistema de representações, pois os seus objectos, marcados que estão pelo sensível, não se prestam a um simples programa de descodificação semântico.

\section{2. As modalidades de sentido}

Embora a expressão seja a base da articulação simbólica, cada forma cultural é capaz de impor as suas próprias modalidades de sentido na organização do real. Que esta organização não aponte para uma mera tradução interpretativa - ou sistematização perspectivística - de um conjunto de factos apreendidos como entidades ontológicas, é um pressuposto fundamental que acompanha o conceito de forma proposto por Cassirer, pois, dada a sua autonomia configuradora, cada forma simbólica apresenta a concepção ímpar de uma realidade distinta. Assim, se se atentar, por exemplo, ao devir da forma na arte e na ciência, verifica-se que as principais modalidades de sentido que ambas envolvem não são 
redutíveis umas às outras. A tríade das funções de articulação, constituída pelas modalidades "expressiva" (Ausdrucksfunktion), "apresentativa" (Darstellungsfunktion) e "significativa" (Bedeutungsfunktion), embora presente em todas as formas simbólicas - e não, como às vezes se diz, que cada modalidade de sentido corresponde a uma determinada forma simbólica -, ganha uma dinâmica diferente quando passamos do universo artístico para o universo científico (Cassirer, 1995: 11) ${ }^{7}$. Se no primeiro há uma unidade inviolável entre as três modalidades, devido à impossibilidade estruturante de serem puramente abstraídas do substrato sensível da obra de $\operatorname{arte}^{85}$, já no segundo há uma maior prevalência da função significativa sobre as demais - o que redunda, por assim dizer, em uma discrição progressiva do sensível face ao abstracto.

Perante esta unidade dada pela arte - sempre que ela seja capaz de se assumir dentro de um espaço cultural autónomo, é claro - e distinguindo-a do sistema de operações simbólicas levadas a cabo pelos agentes da ciência, é possível traçar duas linhas de reflexão que assinalam a organização de uma consciência da forma já dentro do próprio universo cultural concebido e vivido pelo homem. A primeira linha tem como ponto de referência a relação entre arte e percepção, e pode ser traçada a partir do pressuposto teórico de uma descontinuidade epistemológica entre a percepção da obra e a percepção do mundo. $\mathrm{Na}$ arte, o devir da forma encontra-se associado a uma redescoberta da apreensão sensível da realidade, já que, como nos diz Cassirer, a entrada no universo individual da obra permite-nos redireccionar o olhar para todos aqueles fenómenos que, estando sujeitos à habituação dos nossos modos de ver, se tornam discretos na sua manifestação particular (Cassirer, 1996: 221-22). O mesmo é dizer, a experiência da individualidade da obra potencia uma certa emancipação cognitiva dos fenómenos quotidianamente apreendidos, permitindo, nesse intervalo que se abre entre as categorias do individual e do geral, configurá-los sob a luz do particular, do concreto.

Aceitar a ideia de que as formas artísticas não são meros produtos de transferências e projecções das emoções puras do artista, como é sugerido pelas teorias estéticas de Benedetto Croce e Robin George Collingwood, nem tão-pouco simples manifestações figurativas desprovidas de qualquer sentido expressivo, proporciona, de igual modo, uma verdadeira visão das possibilidades abertas pela obra de arte no que à consciência da formação simbólica da 
cultura diz respeito, nomeadamente de todas aquelas possibilidades intrínsecas à passagem da participação cultural para a observação cultural. E, com isto, traça-se a segunda linha de reflexão. Da experiência consciente do devir das formas artísticas, resulta também um momento de exemplificação da morfologia que é comum a todas as formas simbólicas: a articulação inabalável entre sentido e sensibilidade, que, como já referimos, está na génese da dinâmica fundadora do objecto cultural. O que agora nos leva a dizer que da arte desponta uma consciência da "forma", uma consciência emergente da geração da forma na sua acepção mais originária porque a arte nunca põe entre parêntesis a individualidade expressiva dos seus objectos -, resulta do facto de os processos de simbolização estético-artísticos não serem redutíveis a qualquer tradução cultural equivalente, já que neles prevalece sempre uma tensão fundamental entre símbolo e simbolizado, criação e significação.

\section{O mito como matriz genealógica da forma}

A dinâmica dada por cada forma simbólica à tríade das funções de articulação vem suster, desenvolver e intensificar as diferenças estruturantes que a capacidade de simbolizar reserva ao ser humano na sua apreensão quotidiana do mundo. Contudo, nem sempre essa dinâmica é susceptível de uma observação consciente, nem sempre a correlação entre símbolo e simbolizado se inscreve segundo uma lógica da representação, linear e transparente. Como fundamentar tal suspensão da observação consciente dos processos de simbolização? A resposta, segundo Cassirer, deve ser procurada nas operações simbólicas do mito.

O mito como forma simbólica é analisado por Cassirer não com um mero intento classificatório do "primitivo", como em Edward Tylor, ou do "religioso", como em Émile Durkheim, mas antes como um ponto de partida seguro para a compreensão da formação das dinâmicas culturais. Não se trata, por isso, como era ainda visível nas técnicas de comparação elaboradas pela etnologia oitocentista, de submeter uma visão "arcaica" a uma visão "avançada" do mundo, remetendo assim a ideia de cultura para o curso do progresso civilizacional. Bem pelo contrário. Trata-se, sim, de identificar o mitológico já no âmago da própria faculdade simbólica. A ideia de que, com a prevalência e o desenvolvimento de determinadas operações mentais superiores, é paralelamente anulado o arcaísmo mental do bárbaro e do supersticioso, não é acolhida por Cassirer. 
Nem a linearidade epistemológica do evolucionismo histórico, presente na premissa de que o racional é a superação insofismável do irracional, nem tão-pouco a ideia de que o pretenso véu do irracional impede qualquer indagação dos processos e horizontes históricos, são defendidas pelo filósofo alemão. O mito é, pelo contrário, uma parte integrante da articulação simbólica da realidade, nomeadamente a primeira dinâmica estruturante de cada forma simbólica (Cassirer, 1994 ${ }^{4}: 112$ ).

Cassirer é, naturalmente, herdeiro do importante legado deixado por Giambattista Vico e por Friedrich Wilhelm Joseph von Schelling. Se Vico, ao afastar-se de uma certa concepção que via o mito como um mero desvio da razão, vai considerar as formas míticas como partes integrantes da cultura, será, precisamente, na filosofia de Schelling que o mito, considerado a partir do politeísmo da imaginação, irá alcançar uma posição de destaque dentro da reflexão sobre a constituição histórica do espírito humano. O reconhecimento das raízes mitológicas das formas simbólicas serve, de igual modo, para dissipar algumas das visões filosóficas relativas à natureza do mito, principalmente aquelas de cunho positivista que tendiam a associar o mito a uma fase pré-simbólica do espírito humano, e a qual, por sua vez, seria plenamente suplantada com a fundação de uma visão científica do universo.

Contudo, assinalar a relevância cultural do mitológico não redunda em descurar a especificidade morfológica de cada forma simbólica. Encarar o mito como um ponto de observação das práticas humanas tanto permite apurar os elementos novos que são acrescentados à articulação simbólica e à estruturação da imagem que o ser humano faz de si próprio, como objectivar critérios de relação e diferenciação das formas simbólicas. E é considerando ambos os trajectos que podemos vislumbrar as dimensões nocivas que o mito, impondo-se como única força de mediação nos processos intersubjectivos, pode exercer sobre a consciência da cultura. Sabemos que a capacidade de simbolizar não só efectiva e promove a autodeterminação do ser humano, como também o expõe à sua negação, quer dizer, à manipulação - seja esta directamente exercida por si ou por outrem. Entender a manipulação sob o ponto de vista simbólico, significa ver como é que os processos de articulação se deixam penetrar por dinâmicas culturais que conduzem a um desencontro irreparável entre acção e consciência, intencionalidade e responsabilidade. Na opinião de Cassirer, o mito aliado às técnicas das ideologias políticas impõe e 
promove uma verdadeira regressão da consciência simbólica. É principalmente na sua obra póstuma "O Mito do Estado" (Cassirer: 2002) que Cassirer se dedica a mostrar as relações totalitárias que se estabelecem entre ideologias políticas e técnicas de manipulação social. Estas relações totalitárias - como, por exemplo, a ascensão do nacional-socialismo na Alemanha, que é o paradigma histórico do qual Cassirer parte - começam todas por se enraizar graças a um enorme retrocesso sociocultural da consciência simbólica: a consciência é mergulhada num anonimato acrítico, perdendo, com isso, a distância reflexiva dada pelas suas estruturas de "representação", porque, face aos processos de substancialização da realidade e das próprias instituições sociais, passa a ser manipulada através de cerimoniais ritualísticos e de técnicas de repetição da propaganda ideológica.

\section{Mediação e individuação}

A compreensão do conceito de "forma simbólica" permitenos, agora, confrontá-lo com a própria ideia de cultura. E isso não é apenas uma mera operação de síntese. A implicação de um conceito num dado sistema de análise não deve ser entendida somente a partir da função terminológica que ocupa dentro desse mesmo sistema, pois o conceito, não se limitando a dar corpo semântico à ideia, põe também em jogo as diferenças introduzidas pelo próprio sistema na captação do seu objecto de observação. Assim, da articulação entre a ideia de cultura e o conceito de forma simbólica resultam dois momentos estruturantes essenciais:

1) a cultura como uma forma de auscultação das actividades do ser humano, e ancorada em várias modalidades de articulação simbólicas;

2) e a cultura como espaço relacional - e não como um espaço identitário fechado - de experiências de criação e expressão da realidade humana.

O segundo momento é, sem dúvida, aquele que ainda carece de uma fundamentação mais rigorosa, pois vem pôr em causa uma das linhas mais comummente difundidas pelo discurso crítico sobre o estatuto da cultura. Refiro-me, a esse respeito, por exemplo, a uma certa tendência contemporânea das ciências sociais, que, empenhadas em expurgar o vocabulário científico da sua genealogia "bárbara", propõem a erradicação do conceito de cultura de todas as formas de interpretação. $\mathrm{Na}$ maior parte dos casos, a fundamentação dessa erradicação é apoiada no pretenso 
facto de o termo "cultura" ser um sinónimo assaz fiel de "ideologia" ou, até mesmo, de "raça". Tal tendência - ainda que possa ser adjectivada de economicista, visto que intenta suprimir inconsistentemente aquilo que, em rigor, deveria ser explicado e refundado - não é integralmente nova. Embora com outras ramificações conceptuais, ela pode ser inscrita dentro da tradição teórica que se habituou a tecer a crítica do mundo social a partir da sublimação do mundo natural. Desde Jean-Jacques Rousseau que a entrada do ser humano no universo cultural passou a significar, também, a sua saída do universo paradisíaco do mundo natural, lugar esse onde teria, supostamente, permanecido incólume e incorruptível. De facto, na modernidade, as visões negativas da cultura caminham lado a lado com as visões positivas.

Mas o que é importante reter destas tensões teóricas é a relação objectiva que se estabelece entre cultura e individuação. Cassirer não omitiu esta relação. Apesar de ter sido testemunha do florescimento ideológico de discursos etnocêntricos e xenófobos, ele vai distanciar-se de uma interpretação do cultural como ordem impositiva face ao ser humano, mais precisamente como fatalidade irreversível. À Trägodie der Kultur, de Georg Simmel (Simmel: 1983), cuja atmosfera fatalista parece diagnosticar e prognosticar o curso tempestuoso das primeiras décadas do século vinte, responde Cassirer com uma versão oposta, narrada em tom optimista, porque ancorada no princípio, já mencionado anteriormente, do dinamismo estrutural inerente às formas simbólicas. Era toda uma nova concepção que cairia por terra, se se interpretasse a cultura como uma entidade reificada, como uma natureza imposta por um desígnio alheio à energia criadora do ser humano, substancializando-a e encontrado nela única e pretensamente o "carácter", o "típico", o "exótico", a "essência" de um grupo, de uma comunidade, de uma nação. Enquanto operação de compreensão filosófica, a cultura presta-se, pelo contrário, a mostrar a dinâmica da forma, a dialéctica das variáveis e invariáveis que anima cada estrutura de mediação; e, nesse sentido proposto por Cassirer, ela aponta para a possibilidade inesgotável de a individuação ser permanentemente inscrita e recriada, já que, na base do dinamismo estrutural de cada forma simbólica, está, originariamente, a articulação capital entre sensibilidade e sentido. Quer isto dizer: os processos de individuação não são como que decalcados a posteriori de percepções e intelecções já instituídas, mas antes têm o seu início com a articulação da própria experiência sensível. É 
também nesse sentido que os objectos e as obras culturais devem ser interpretados. Abertos à mutabilidade, à dinâmica da forma, eles permitem-nos observar as possibilidades de uma auto-realização livre dos indivíduos.

Com efeito, assim entendidos, os processos de individuação não se deixam traduzir literalmente no desígnio de progresso veiculado pela Aufklärung. Admitir tal premissa racionalista seria partir do pressuposto que as formas simbólicas estariam configuradas teleologicamente - segundo um programa racional avesso às mutações históricas -, condizendo, nessa medida, o fulcro do progresso com a supremacia de umas e a total desaparição de outras, como, aliás, se pode inferir da lógica da superação do pensamento mítico pelo conhecimento científico. Em vez disso, o que é aventado prende-se com o reconhecimento da tensão entre as várias formas simbólicas, que, longe de derivar de um essencialismo morfológico, de uma pregnância originária, tende sempre a emergir dos desafios que a vida social imprime no ser humano. São as actividades desenvolvidas por este último que animam a possibilidade de as articulações simbólicas servirem o interesse de uma racionalidade libertadora e mobilizadora, não havendo, nesse sentido, uma pura antecipação da razão a todas as operações simbólicas, nem sequer a supressão destas face a um estádio cultural superior mediado pelo consenso.

Quer a liberdade quer a responsabilidade implicam que 0 sujeito se consciencialize como agente "cultural". A elaboração de campos de acção e de experiências do mundo pressupõem uma alteridade expressiva, isto é, modalidades de mediação que permitem dar comunicabilidade à diferença e à identidade que são geradas no universo social. Partindo da máxima cassireriana de que as formas simbólicas têm uma relativa autonomia entre si, ou melhor, manifestam marcas estruturais específicas que inscrevem a nossa experiência dentro de uma pluralidade de horizontes de sentido - sendo, nessa exacta medida, o mundo as "versões do mundo" -, tornar-se-á, por isso, imperioso concluir que as relações entre estas versões - relações de identidade e diferença, por exemplo - não são intuídas a partir de uma substancialidade espiritual comum a todas elas, nem se prestam a um apuramento ontológico do "mundo" que articulam. Bem pelo contrário. A possibilidade de uma versão do mundo entrar em relação com uma outra envolve, permanentemente, actividades socioculturais ancoradas em processos de expressão e de comunicação (Gessner; 
Schwemmer, 2010: 207). E transferir este propósito para a esfera individual dos agentes envolvidos em tais processos, implica, por sua vez, reconhecer a possibilidade de o "eu", se confrontado com modalidades de articulação emergentes, vivenciar e interiorizar novas formas de individuação.

\section{Conclusão}

Em suma, entender a ideia de cultura como uma forma de percepção teórica das relações humanas nos seus contextos histórico-sociais, mormente daquelas que são mediadas através de estruturas e sistemas simbólicos, não significa, porém, conceber essa forma de percepção segundo uma lógica de equivalências entre mediações simbólicas e ideia(s) de cultura. As dimensões dialógicas das relações socioculturais - apoiadas na articulação de horizontes de sentido - não implicam, per se, graus de observação idênticos da ideia de cultura que partilham e promovem. É à luz desta diferença basilar que devemos situar a ideia de cultura dentro de dinâmicas de intermutabilidade entre participação na cultura e observação da cultura, anulando, por conseguinte, os efeitos de uma semântica clássica ainda apoiada na mera divisão entre vita activa e vita contemplativa, entre observados e observadores. Se a exploração das capacidades simbólicas do ser humano tende a propiciar o aparecimento de novas formas simbólicas, bem como de novas relações entre elas, a cultura deve ser interpretada como uma resposta fundamental de reflexão e consciencialização das diferenças que se vão inscrevendo no universo social. Será, pois, nesta possibilidade de resposta - e não na sua compreensão como fatalidade herdada - que a ideia de cultura deve encontrar o seu fundamento.

\section{Referências/Bibliografia}

Baecker, D. (2003). Wozu Kultur? Berlin: Kulturverlag Kadmos.

Bourdieu, P. (1974). Zur soziologie der symbolischen Formen.

Frankfurt am Main, Suhrkamp Verlag.

Cassirer, E. (1994). Philosophie der symbolischen Formen, Erster

Teil: Die Sprache. Darmstadt: Wissenschaftliche Buchgesellschaft.

Cassirer E. (1994²). Philosophie der symbolischen Formen, Zweiter

Teil: Das mythische Denken. Darmstadt: Wissenschaftliche Buchgesellschaft.

Cassirer, E. (1994³). Philosophie der symbolischen Formen, Dritter

Teil: Phänomenologie der Erkenntnis. Darmstadt: Wissenschaftliche Buchgesellschaft. 
Cassirer, E. (1995). Symbol, Technik, Sprache. Aufsätze aus den Jahren 1927-1933. Hamburg: Felix Meiner Verlag.

Cassirer, E. (1996). Versuch über den Menschen. Einführung in eine Philosophie der Kultur. Hamburg: Felix Meiner Verlag.

Meiner Verlag.

Cassirer, E. (2002). Vom Mythus des Staates. Hamburg: Felix

Cassirer, E. $\left(1994^{4}\right)$. Wesen und Wirkung des Symbolbegriffs. Darmstadt: Wissenschaftliche Buchgesellschaft.

Cassirer, E. (1989). Zur Logik der Kulturwissenschaften: fünf Studien. Darmstadt: Wissenschaftliche Buchgesellschaft.

Gessner, W.; Schwemmer, O. (2010). Geist und Kultur. Berliner Philosophie 1885-1945. In T. von Heinz-Elmar; V. Hess; D. Hoffmann (Eds.), Geschichte der Universität Unter den Linden 1810-2010, Band 5: Transformation der Wissensordnung, 175-214. Berlin: Akademie Verlag.

Goodman, N. (1990). Weisen der Welterzeugung. Frankfurt am Main: Suhrkamp Verlag.

Kant, I. (1923). Idee zu einer allgemeinen Geschichte in weltbürgerlicher Absicht. In Kant's Gesammelte Schriften, Bd. 8. Berlin und Leipzig: Walter de Gruyter \& Co.

Kant, I. (1908). Kritik der Urteilsktaft. In Kant's Gesammelte Schriften, Bd. 5. Berlin: Verlag von Georg Reimer.

Kapp, E. (1877). Grundlinien einer Philosophie der Technik. Zur Entstehungsgeschichte der Kultur aus neuen Gesichtspunkten. Braunschweig: Verlag George Westermann.

Lotman, Yu. M.; Uspensky, B. A. (1978). On the Semiotic Mechanism of Culture. New Literary History, 9, 2 (1978) 211-232.

Luhmann, N. (1985). Kultur als historischer Begriff. In Gesellschaftsstruktur und Semantik. Studien zur Wissenschaftssoziologie der modernen Gesellschaft, Band 4, 31-54. Frankfurt am Main: Suhrkamp Verlag.

Panofsky, E. (1974). Die Perspektive als symbolische Form. In Aufsätze zu Grundfragen der Kunstwissenschaft, 99-167. Berlin: Haude \& Spencer.

Simmel, G. (1983). Der Begriff und die Tragödie der Kultur. In Philosophische Kultur. Über das Abenteuer, die Geschlechter und die Krise der Moderne. Gesammelte Essais, Mit einem Nachwort von Jürgen Habermas, 183-207. Berlin: Verlag Klaus Wagenbach.

Tylor, E. B. (2010). Primitive Culture: Researches into the development of Mythology, Philosophy, Religion, Art, and Custom. Cambridge: Cambridge University Press.

White, L. A. (1959). The concept of culture. American Anthropologist, 61 (1959) 227-251.

White, L. A. (19592). The evolution of culture. The development of civilization to the fall of Rome. New York: McGraw-Hill Book Company. 


\section{${ }^{1}$ A new look at a philosophical itinerary: From the idea of culture to the concept of symbolic form \\ ${ }^{2}$ Doutor.}

Universidade de Coimbra (Portugal). I\&D LIF - Linguagem, Interpretação, Filosofia.

Email: joaquim.braga@yahoo.com

${ }^{3}$ A distinção de Kant não só põe em jogo a oposição moral entre cultura e civilização, como também particulariza as formas de conhecimento que constituem a Bildung do sujeito cultivado: "Somos cultivados em alto grau pela arte e pela ciência. Somos civilizados, até ao excesso, para tudo quanto diz respeito à cortesia e às boas condutas sociais. Mas ainda nos falta muito para nos podermos já julgar moralizados. Porque a ideia da moralidade pertence ainda à cultura; mas a aplicação dessa ideia, restringida apenas à aparência de moralidade no amor da honra e da decência exterior, funda somente a civilização.» (Wir sind im hohen Grade durch Kunst und Wissenschaft cultivirt. Wir sind civilisirt bis zum Überlästigen, zu allerlei gesellschaftlicher Artigkeit und Anständigkeit. Aber uns für schon moralisirt zu halten, daran fehlt noch sehr viel. Denn die Idee der Moralität gehört noch zur Cultur; der Gebrauch dieser Idee aber, welcher nur auf das Sittenähnliche in der Ehrliebe und der äußeren Anständigkeit hinausläuft, macht blos die Civilisirung aus) (Kant, 1923: 15$31 ; 26)$.

4 Sobre os pressupostos semânticos do conceito de cultura na reflexão da Systemtheorie, vide, por exemplo, Baecker, 2003: 44-111.

${ }^{5} \mathrm{O}$ uso de ambos os termos é logo referido no início da sua obra sobre a cultura primitiva: «Culture or civilization, taken in its wide ethnographic sense, is that complex whole which includes knowledge, belief, art, morals, law, custom, and any other capabilities and habits acquired by man as a member of society.» (Tylor, 2010: 1). No entanto, a noção de cultura proposta por Tylor não é propriamente uma definição científica. Trata-se, em rigor, de utilizar o termo "cultura" para submeter algumas manifestações colectivas - como a arte e os costumes - a um sistema transparente de identidades sociais.

${ }^{6}$ Uma visão puramente semiótica do conceito de cultura pode ser encontrada, por exemplo, em Lotman; Uspensky, 1978.

7 Erwin Panofsky, na sua obra Die Perspektive als symbolische Form, serve-se, precisamente, da ideia de articulação entre sentido e sensibilidade, incluída no âmago teórico da definição cassireriana de forma simbólica, para mostrar as fundações e as transmutações histórico-culturais da arte pictórica (Panofsky, 1974: 108). E Pierre Bourdieu, seguindo a aplicação de Panofsky do conceito de forma simbólica, vai propor a noção de "campo artístico" para situar as estruturas simbólicas da arte dentro da lógica cultural das instituições sociais, afastando-se assim das concepções estético-artísticos do "olhar puro" (Bourdieu, 1974).

${ }^{8}$ Aquilo que começa por distinguir a modalidade expressiva das outras funções simbólicas assenta, acima de tudo, na relação imediata que ela tende a gerar com as operações sensoriais (Cassirer, 19943: 80). Esta correlação entre expressão e percepção faz com que, em muitos objectos culturais, a distância entre símbolo e simbolizado não seja plenamente estabelecida, o que favorece, nesse sentido, a intensidade do valor afectivo dos objectos, ou, noutros casos, a violência exercida pelos mesmos. A modalidade expressiva, detendo um sentido espontâneo que não é facilmente apreendido pela consciência reflexiva, permanece ligada à sensibilidade e à corporalidade. É com a modalidade apresentativa que verdadeiramente se opera uma distância consciente entre símbolo e simbolizado; distância essa que se mostra indispensável para a articulação da linguagem e para a própria objectivação das 
formas artísticas. No que à modalidade significativa (pura) diz respeito, existe um maior grau de abstracção simbólico, pois os elementos sensíveis da forma deixam de ter um papel relevante na relação entre símbolo e simbolizado, como se verifica, por exemplo, nas operações matemáticas. 